\title{
Bycatch and strandings programs as ecological indicators for data-limited cetaceans
}

\author{
Justin J. Meager ${ }^{\mathrm{a}, *}$, Wayne D. Sumpton ${ }^{\mathrm{b}}$ \\ a Queensland Department of Environment and Heritage Protection, GPO Box 2454, Brisbane, Queensland 4001, Australia \\ ${ }^{\mathrm{b}}$ Queensland Department of Agriculture and Fisheries, GPO Box 267, Brisbane, Queensland 4001, Australia
}

\section{A R T I C L E I N F O}

\section{Article history:}

Received 13 February 2015

Received in revised form 28 August 2015

Accepted 31 August 2015

\section{Keywords:}

Bycatch

Strandings

Cetaceans

Dolphins

Whales

\begin{abstract}
A B S T R A C T
An integrated approach of using strandings and bycatch data may provide an indicator of long-term trends for data-limited cetaceans. Strandings programs can give a faithful representation of the species composition of cetacean assemblages, while standardised bycatch rates can provide a measure of relative abundance. Comparing the two datasets may also facilitate managing impacts by understanding which species, sex or sizes are the most vulnerable to interactions with fisheries gear. Here we apply this approach to two long-term datasets in East Australia, bycatch in the Queensland Shark Control Program (QSCP, 1992-2012) and strandings in the Queensland Marine Wildlife Strandings and Mortality Program (StrandNet, 1996-2012). Short-beaked common dolphins, Delphinus delphis, were markedly more frequent in bycatch than in the strandings dataset, suggesting that they are more prone to being incidentally caught than other cetacean species in the region. The reverse was true for humpback whales, Megaptera novaeangliae, bottlenose dolphins, Tursiops spp.; and species predominantly found in offshore waters. QSCP bycatch was strongly skewed towards females for short-beaked common dolphins, and towards smaller sizes for Australian humpback dolphins, Sousa sahulensis. Overall, both datasets demonstrated similar seasonality and a similar long-term increase from 1996 until 2008. Analysis on a species-byspecies basis was then used to explore potential explanations for long-term trends, which ranged from a recovering stock (humpback whales) to a shift in habitat use (short-beaked common dolphins).
\end{abstract}

Crown Copyright (c) 2015 Published by Elsevier Ltd. All rights reserved.

\section{Introduction}

A fundamental issue in conservation management of cetaceans is obtaining accurate data on population structure and abundance for species that are characteristically highly mobile over vast areas or that are rarely encountered (Magera et al., 2013). Monitoring abundance over time scales that are meaningful for species with long generation times can also be prohibitively expensive, especially when approaches such as mark-recapture or distance sampling are required. Consequently, species or stocks may be categorised as data deficient and may not be afforded an appropriate level of protection.

In recent years, it has been increasingly realised that critical demographic (Mannocci et al., 2012), genetic (Bilgmann et al., 2011) and species diversity information (Pyenson, 2010, 2011) can be obtained from relatively inexpensive strandings networks, particularly if they encompass a large area and are collected over

\footnotetext{
* Corresponding author. Tel.: +61 73170 5621; fax: +61 731705800.

E-mail address: Justin.Meager@gmail.com (J.J. Meager).
}

long time periods. Strandings records also provide information on species that are rarely observed in the wild (Thompson et al., 2013) and the frequency of occurrence of species within an area (Maldini et al., 2005). However, the relationship between strandings records and population trends in live assemblages can be confounded by a range of factors such as unusual stranding events (e.g. epizootics or mass strandings), environmental variation (Meager and Limpus, 2014), carcass drift (Peltier et al., 2012) or reporting effort. It is also arguable whether strandings records represent the demographics of living communities, because the risks of mortality or morbidity characteristically vary with ontogeny (Perrin et al., 2002).

Incidental take in fisheries, or bycatch, is another source of data often collected for cetaceans. In cases where the data are reliable, such as when they are overseen by an observer program, and when gear-related effects are accounted for, standardised bycatch may provide an index of population abundance over time (Maunder and Punt, 2004). This approach has underpinned many analyses of recovery trends and hindcasts of historical population sizes of marine mammals (e.g. Baker and Clapham, 2004; Marsh et al., 2005; Christensen, 2006; Magera et al., 2013). Yet, there are many examples of known biases from using standardised bycatch as an 
ecological indicator, for example, if extrinsic factors make animals more likely to interact with fishing gear during certain time periods (Harley et al., 2001). Comparing bycatch rates with strandings records may alleviate some of these concerns by providing fisheries-independent reference points.

Monitoring bycatch is also important in its own right, because incidental catch in some fisheries poses a significant global threat to many cetacean species (Lewison et al., 2004; Read et al., 2006; Leeney et al., 2008). An important step towards mitigating bycatch is in understanding which species, sexes, ages or individuals are vulnerable to capture. To this end, much can be ascertained by comparing catch rates between gear types, or better still, against independent data such as that provided by dedicated surveys or strandings programs.

Here we analyse two long-term datasets in eastern Australia, the Queensland Shark Control Program (QSCP) and the Queensland Marine Wildlife Strandings and Mortality Program (StrandNet). Specifically, we examine long term and seasonal trends in cetacean bycatch and strandings, and explore the usefulness of this comparative approach as an ecological indicator for data-limited species across a subtropical-tropical coastline spanning more than $2000 \mathrm{~km}$. We also compare the species, size and sex composition of cetaceans between gear and datasets to investigate gear selectivity and dataset biases.

\section{Materials and methods}

\subsection{Queensland Shark Control Program (QSCP)}

The QSCP uses surface-set nets and baited hooks (drumlines) to remove potentially dangerous sharks from the vicinity of popular bathing areas in the state of Queensland, in Australia's north east, and has been in place since 1962 . While it is not a commercial fishery, it uses fisheries gear to catch target species, and non-target bycatch species such as other elasmobranches, teleost fishes, marine turtles and marine mammals are caught in the process (Sumpton et al., 2011). For the purposes of this study, we define 'bycatch' as non-target animals that have become hooked or entangled on QSCP drumlines or nets, that were either dead or that required human intervention to release alive. Cases of brief entanglement, where the animal freed itself, or where damage to gear occurred for unknown reasons were not included.

Cetacean bycatch in the QSCP has been routinely recorded since 1974, but dolphins were rarely identified to species prior to 1992 (Gribble et al., 1998). From 1992, a number of initiatives including trained observers, covert surveillance and training in species identification were undertaken to improve the quality of the bycatch data. Here we analyse data from 1992 to 2012, when nets and drumlines were set at Cairns, Mackay, Rainbow Beach, the Sunshine Coast and the Gold Coast; and drumlines were set at an additional five regions (Fig. 1).

Data were first screened for data entry or misidentification errors, based on knowledge of the geographic range of species and whether other confirming data such as photos and genetic samples were available. Where there was considerable uncertainty, discussions were then held with the relevant fisheries contractor. Cases were changed to 'unidentified' where identification could not be resolved.

Operational aspects of gear deployment in the QSCP were described in detail by Sumpton et al. (2011). Briefly, nets are constructed of $1.6 \mathrm{~mm}$ diameter polypropylene mesh with a stretched-mesh size of $50 \mathrm{~cm}$, a drop of $6 \mathrm{~m}$ and a total length of $186 \mathrm{~m}$. Drumlines consist of a single 14/0 shark hook baited with fresh sea mullet (Mugil cephalus) or shark flesh suspended from a buoy at least $2 \mathrm{~m}$ from the seafloor at low tide. Drumlines and nets are anchored to the seafloor and set parallel to the shore in water between 6 and $12 \mathrm{~m}$ deep, approximately $600 \mathrm{~m}$ from the shore, although this distance varies depending on local topography. Nets and drumlines are checked and rebaited (in the case of drumlines) 15-20 days per month by contracted fishers. Each day the gear is checked, the contractors record details of the shark catch and bycatch, including species, sex, total length and the state of each animal (alive or dead).

No major changes in gear placement, deployment or configuration occurred in the time period and regions analysed, with the exception of the incremental introduction of acoustic pingers. Whale pingers (fundamental frequencies from 2.7 to $5 \mathrm{kHz}$ ) were tested on the Gold Coast during the whale migration seasons of 1992 and 1993 (Gribble et al., 1998). They were subsequently used during the whale migration season on the Gold Coast nets (since 1994) and on the Sunshine Coast (since 1997) (Lien et al., 1996). Dolphin pingers (Fumunda F10 or similar $10 \mathrm{kHz}$ pingers) were incrementally deployed from 1994 to 1995 (Gribble et al., 1998). Fumunda F70 dolphin pingers ( $70 \mathrm{kHz}$ ) have also been trialled since 2012.

\subsection{The Queensland Marine Wildlife Strandings and Mortality Program (StrandNet)}

Stranded cetaceans are recorded in the StrandNet database for the state of Queensland (Meager and Limpus, 2014). For the purposes of the current study, we use the term 'strandings' for cetaceans that were reported to be in ill health, injured, incapacitated or dead, whether beach cast or observed at sea. Records are obtained from government departments, environmental organisations and the general public, and include information such as location, date, sex, body-size measurements, and carcass condition. All records are verified by trained staff or species experts. The probable cause of death is established through examination of carcasses by trained staff, necropsies by veterinarians or, in some cases, through photos and/or case histories.

Cetacean strandings have been systematically recorded along the east coast of Queensland, Australia from Cairns to the Queensland-New South Wales border since 1996. Cetacean strandings attract significant attention from the public and there are few locations along the coastline where beach-washed cetaceans are not reported. The proportion of carcasses or debilitated animals that reach the shoreline is unknown, and is likely to depend on factors such as currents, wind and carcass buoyancy, and losses to scavengers (Peltier et al., 2012). Cetaceans are also reported floating dead or debilitated at sea. Coverage at sea is the most comprehensive in areas of high vessel traffic or where regular patrols are conducted.

Data for the time period from January 1996 to December 2012 were first filtered to remove records associated with QSCP bycatch (which are also recorded in StrandNet). Records known to be associated with entanglement or incidental capture in recreational or commercial fisheries, or entanglement in discarded fishing gear were then removed ( $10 \%$ of records). This increased the independence of the strandings dataset from QSCP bycatch because species that interact with QSCP gear could reasonably be expected to interact with recreational and commercial fisheries gear. The coordinates of each stranding event were then used to assign data to QSCP regions (Fig. 1), and data outside of QSCP regions were excluded ( $18 \%$ of records). Finally, we filtered the data for spatial-temporal clusters that could confound the interpretation of the strandings record as an ecological indicator, using a space-time permutation scan test in the program SatScan (Kulldorff et al., 2005; following Norman et al., 2012). This analysis detected one significant cluster of four unidentified small whales on 10/08/2002 (test statistic $=12.7 ; p=0.001)$. These cases were excluded from further 


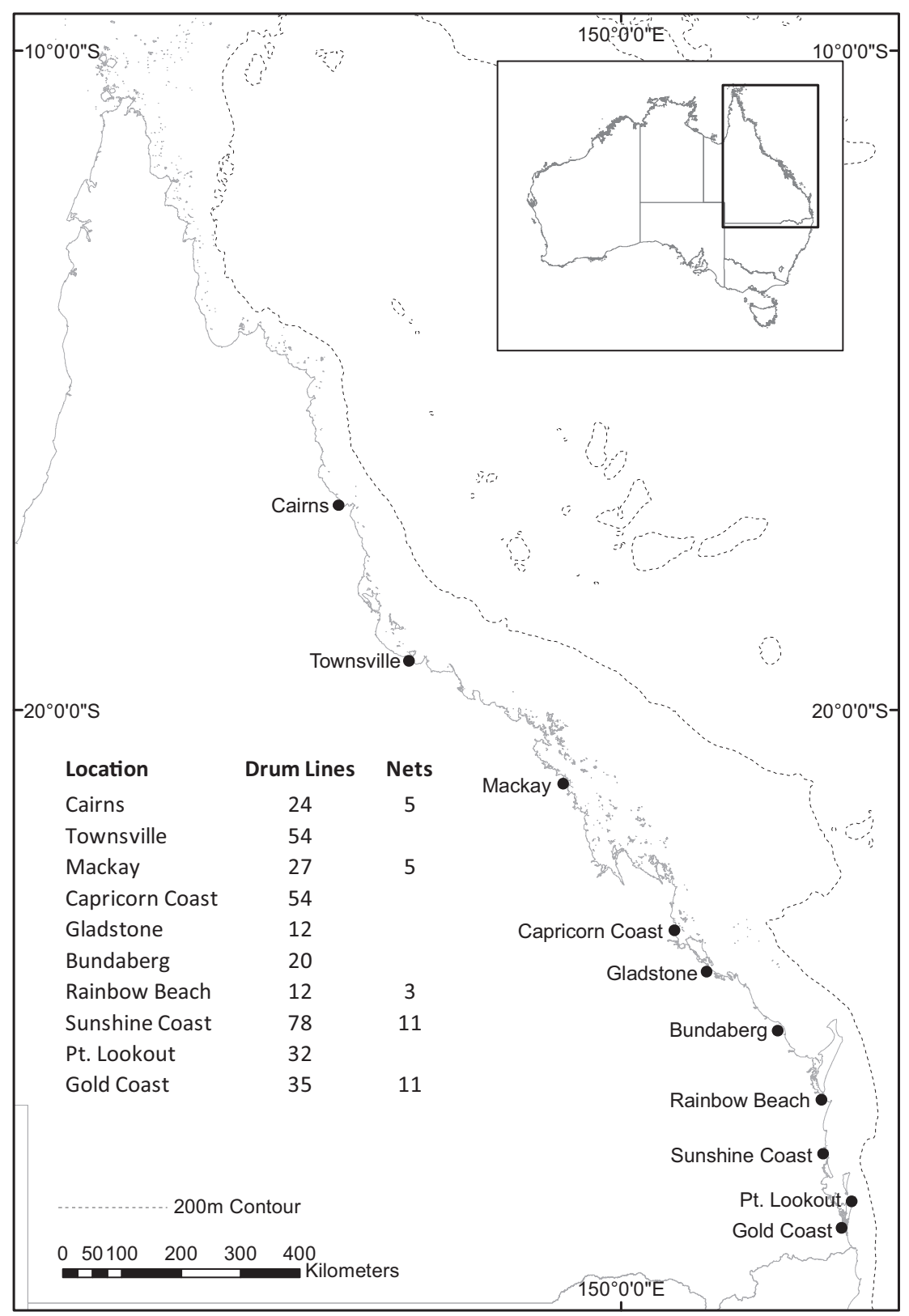

Fig. 1. Locations of Queensland Shark Control Program (QSCP) gear (nets and drumlines) (1992-2012).

analysis, leaving 642 records that were analysed further. No significant clusters were detected in the remaining dataset $(p<0.05,999$ permutations).

\subsection{Species composition}

Species composition was compared between regions and datasets (QSCP and StrandNet) for the time period when data were available from both datasets (1996-2012) using a permutation MANOVA (PERMANOVA+ package of PRIMER v6, Anderson et al., 2008). The analysis was based on Bray-Curtis dissimilarities calculated from fourth-root transformed numbers of individuals, and included the fixed effects of region and dataset. A dummy variable was added to account for undefined resemblances. For our permutation method, we selected permutation of residuals under a reduced model, with a Type III sum of squares and 10,000 permutations. Pair-wise permutation tests were used to compare treatment levels.

\subsection{Temporal trends in bycatch}

Temporal trends of QSCP bycatch were examined using a mixedeffect modelling approach, which accounted for varying bycatch rates and effort between regions by treating region as a random intercept. Only regions where most cetaceans were caught were included (Cairns, Rainbow Beach, the Sunshine Coast and the Gold Coast). Cetacean bycatch was low and zero catch was often recorded for a given month and region. For this reason, the goodness-of-fit of four mixed models was first compared: Poisson, zero-inflated Poisson, negative binomial and a Gaussian model on $\log _{\mathrm{e}}(x+1)$ transformed data (following Warton, 2005). A negative binomial model was judged to be the best fit based on residual diagnostics and Akaike's Information Criterion (AIC). Autocorrelation was also 
evident in the dataset because of seasonality in catches, and was modelled by a trigonometric time-series function (Pinheiro and Bates, 2000). The final model was given by:

bycatch $_{i} \sim N B\left(\mu_{i}, k\right)$

$\operatorname{Var}\left(\right.$ bycatch $\left._{i}\right)=\mu_{i}+\frac{\mu_{i}^{2}}{k}$

$\mu_{i}=e^{\alpha+\beta \sin (2 \pi t)+\gamma \cos (2 \pi t)+f_{1}(\text { year })+b_{i}+\varepsilon_{i}}$

where bycatch $_{i}$ is cetacean bycatch for each region $i$; NB is a negative binomial with a mean of $\mu_{i}$ and a dispersion parameter of $k$; $\alpha$ is the general intercept; $t$ is calendar month (coded as 1-12 and divided by 12); $\beta$ and $\gamma$ are fixed effects defining the amplitude of the cosine wave; $b_{i}$ is the random intercept for each region and $\varepsilon_{i}$ is residual error with a normal distribution. The relationship between bycatch and year was described by a non-linear smoothing function $\left(f_{1}\right)$, because there was no a priori expectation of a linear relationship. Generalised additive mixed models (GAMM) were fitted using the 'mgcv' (version 1.7-247, Wood, 2006) and 'MASS' packages (version 7.3-35, Venables and Ripley, 2002) of the R software environment (version 3.0.1, R Core Team, 2015).

A similar GAMM model was used to test for changes in cetacean bycatch standardised by the number of nets (monthly catchper-unit-effort, CPUE) across the same time series. This model accounted for minor changes to gear deployment in the study period, such as the seasonal removal of some nets during the humpback whale migration season. Drumline bycatch was not included in this analysis because most cetaceans were caught in nets (Paterson, 1990; Gribble et al., 1998; Sumpton et al., 2011). Region was again treated as a random intercept and the same regions were included as above. Total monthly bycatch for each region was converted into monthly CPUE using historical records of nominal effort, which was defined as the number of nets deployed in a region per month. CPUE was first calculated for each month and beach, and averaged over each month and region. CPUE data were log-normally distributed and were thus normalised by $\log _{e}(x+1)$ transformation and analysed using a Gaussian GAMM.

\subsection{Temporal trends in strandings}

Strandings data were also normalised by $\log _{e}(x+1)$ transformation and analysed using a Gaussian GAMM. The annual trend in strandings data was modelled using the same general model as was used for the QSCP data, with the exception that seasonal effects were modelled using a cubic-spline function of month (coded from 1 to 12 , Wood, 2006) rather than a trigonometric time series component. In order to graphically compare seasonal patterns between the QSCP and strandings datasets we fitted GAMM models with cubic-spline functions to both datasets.

\subsection{Bycatch selectivity}

We then investigated the selectivity and fine-scale attributes of bycatch in the QSCP. Firstly, we tested whether the sex ratio of bycatch for each species deviated from random with binomial tests. In species for which sample sizes were adequate, we compared the length-frequency distributions of cetaceans caught in the QSCP with those recorded in the StrandNet dataset, and between gear types in the QSCP, using Kolmogorov-Smirnov tests. Binomial tests were also used to test whether the location of entanglement in nets (i.e. landward or seaward) deviated from random. Finally, we compared the relative survival of cetaceans caught in nets and drumlines using logistic regression. Nested log-likelihood ratios
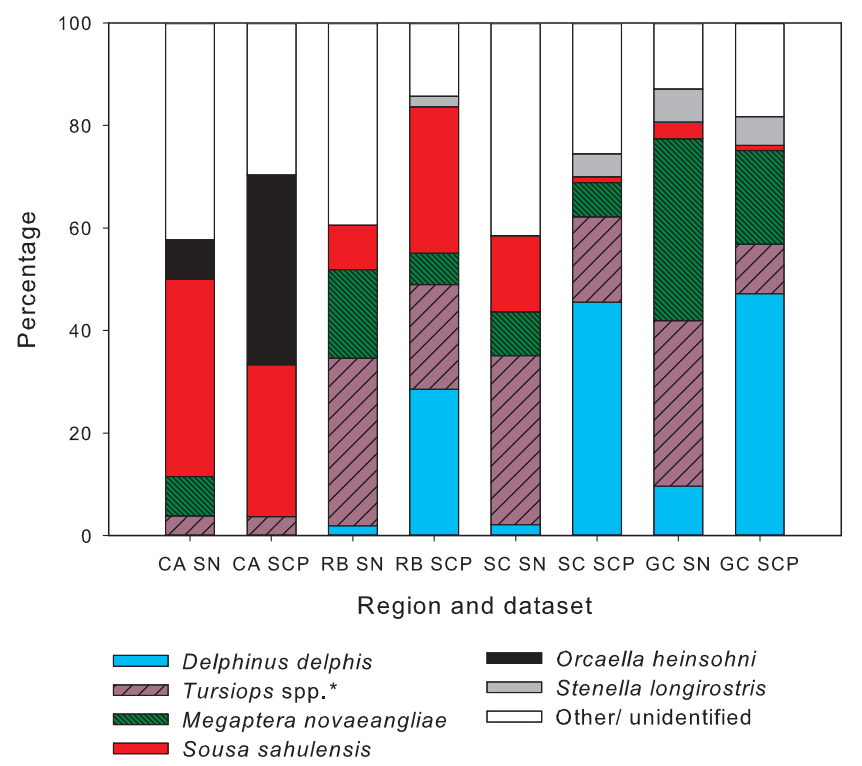

Fig. 2. Species composition (\% occurrence) of bycatch in the Queensland Shark Control Program (QSCP) and strandings (StrandNet database, $\mathrm{SN}$ ) for regions where most bycatch was recorded (CA, Cairns; RB, Rainbow Beach; SC, Sunshine Coast and GC, Gold Coast) (1996-2012). *Tursiops aduncus and Tursiops truncatus were not identified to species in the QSCP.

were used to test for differences in relative survival over time and between regions.

\section{Results}

\subsection{Species composition of bycatch compared to strandings records}

Species composition differed significantly between the QSCP and StrandNet datasets for the time series analysed (1996-2012) (data set: pseudo $F=16.4, p<0.01$ ), but the extent of these differences varied between regions (region: pseudo $F=15.4, p<0.01$; dataset $\times$ region: pseudo $F=5.5, p<0.01$ ) (Fig. 2 ). No difference was evident between datasets for the Cairns region $(t=1.3, p=0.19)$ and the differences were most pronounced on the Gold Coast $(t=3.9, p<0.01)$. Significant differences were also evident between datasets for the Sunshine Coast $(t=3.2, p<0.01)$ and Rainbow Beach $(t=2.7, p<0.01)$. Overall, species composition varied much more between regions (estimated multivariate component of variation $=421.7,22 \%$ of total variation) than between datasets (estimated multivariate component of variation $=224.9,12 \%$ of variation), or between region and datasets (estimated multivariate component of variation $=265.1,14 \%$ of variation ). Nevertheless, a number of general trends were evident across all the regions examined (Fig. 2): (1) more species were recorded in the StrandNet dataset than in the QSCP dataset, (2) short-beaked common dolphins (Delphis delphis) were proportionally much more frequent in the QSCP dataset than in the StrandNet dataset, (3) bottlenose dolphins (Tursiops spp.) and humpback whales (Megaptera novaeangliae) were proportionally more frequent in the StrandNet dataset than in the QSCP dataset.

Of the rarer species, spinner dolphins (Stenella longirostris) were proportionally more frequent in the QSCP dataset (16 cases) than in the corresponding StrandNet dataset ( 0 cases), and a number of taxa were recorded more than five times in the StrandNet dataset but not in QSCP dataset (melon-headed whales, Peponocephala electra, 20 cases; minke whales, Balaenoptera acutorostrata, 7 cases, and sperm whales, Physeter macrocephalus, 7 cases). 

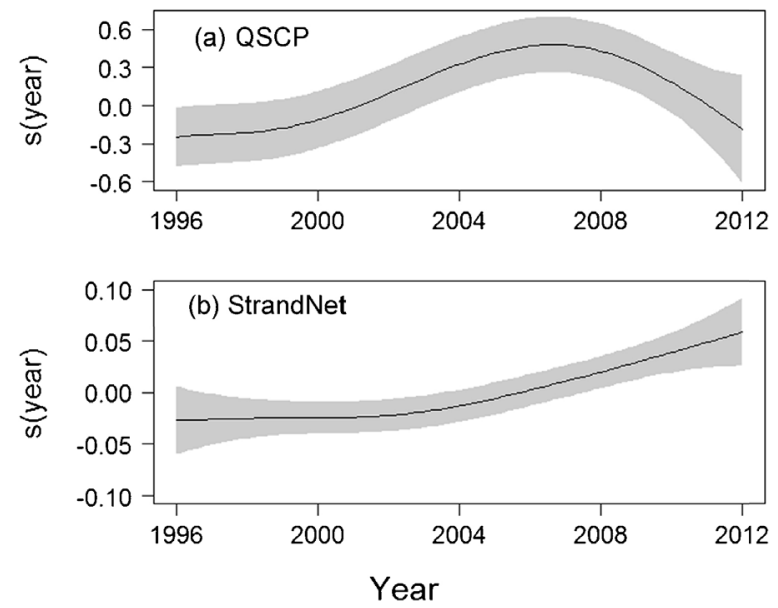

Fig. 3. Comparison of annual trend in (a) cetacean bycatch in the Queensland Shark Control Program (QSCP) and (b) strandings in StrandNet for the period when data were available from both datasets (1996-2012). In each figure, the solid line is the smoother from the final GAMM model and the shaded area represents the 95\% confidence intervals.

\subsection{Spatial-temporal trends in cetacean bycatch and stranding rates}

QSCP cetacean bycatch increased significantly between 1992 and 2008, followed by a decline from 2009 to $2012(F=6.0, p<0.01$; estimated degrees of freedom, edf $=3.6$, Fig. $3 a$ ). This trend was very similar in the CPUE data (Fig. S1 in supplementary data). The StrandNet dataset indicated an overall increase in strandings from 1996 to $2012(F=8.3, p<0.01$; edf $=2.1$, Fig. $3 b)$.

Examination of bycatch data for each region separately indicated increasing annual trends in the southern regions (Rainbow Beach, Sunshine Coast and the Gold Coast) (Fig. S2 in supplementary data). However, the long-term trend in northern Queensland (Cairns) was more variable, and did not demonstrate the same increasing trend evident in southern Queensland. Catches of shortbeaked common dolphins and humpback whales were largely responsible for the overall increase in cetacean bycatch (Fig. 4a).

Detailed examination of the strandings data, and generalised additive models fitted separately to each QSCP region indicated that increases in strandings were also the most pronounced in southern Queensland (Moreton Bay and the Sunshine Coast). The long-term increase in the rate of annual strandings was not because of a single species (Fig. 4b), but rather because of increases across a range of taxa, especially humpback whales, bottlenose dolphins and Australian humpback dolphins (Sousa sahulensis).

\subsection{Seasonality}

On average, the seasonal peak in QSCP cetacean bycatch occurred late austral winter-early spring (sine coefficient $=-0.34$ : $t=-3.5, p<0.01$; cosine coefficient $=-0.3 ; t=-3.4, p<0.01$, Fig. 5a). Although there were insufficient data to fit full GAMMs for each individual species, graphical examination of the data indicated a likely influence of the seasonal migrant, humpback whales, on the overall model. Humpback whale bycatch was the highest in September and October. When humpback whales were excluded from the analysis, and only dolphins were examined, average bycatch peaked in June (Fig. S3 in supplementary data).

The overall seasonal trend was very similar for the StrandNet data, with the highest strandings rates again occurring from late austral winter-early spring (Fig. $5 b, F=112.2, p<0.01$; edf $=4.2$ ) and a peak in August. Excluding humpback whales from this analysis
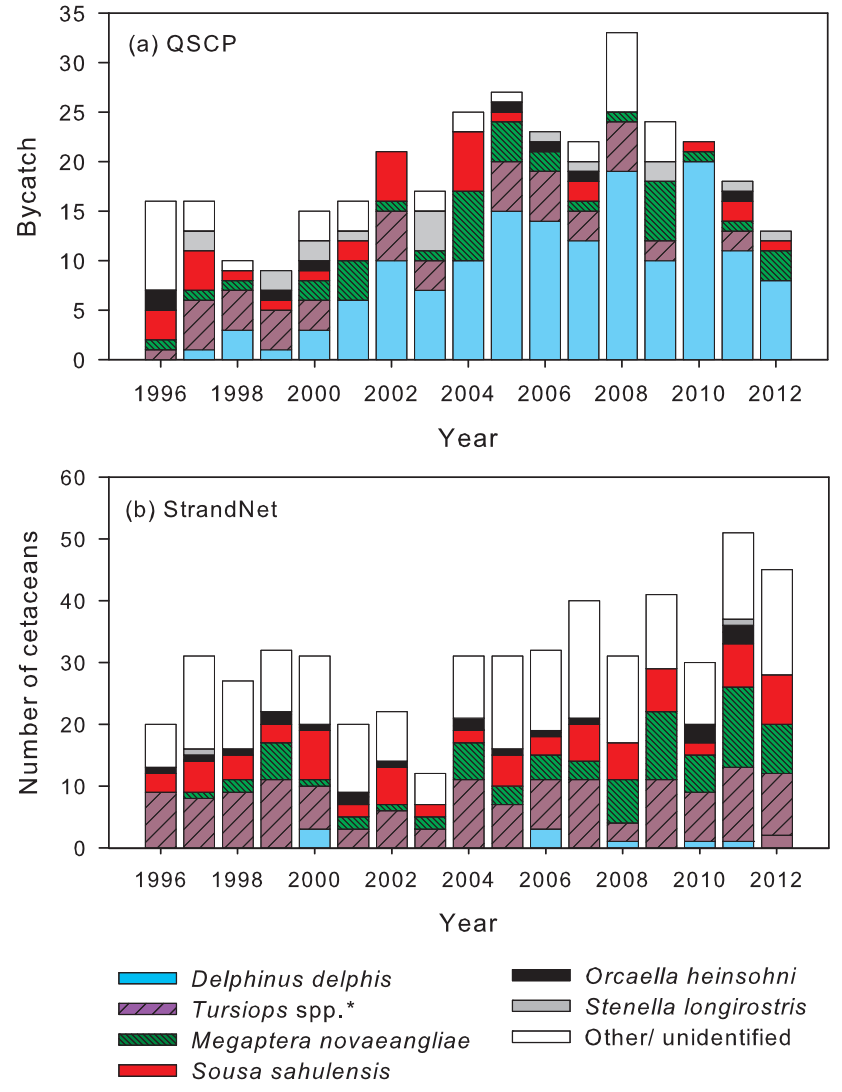

Fig. 4. (a) Queensland Shark Control Program (QSCP) bycatch by species and year from 1996 to 2012, and (b) records in StrandNet by species and year for the same time period. *Tursiops aduncus and Tursiops truncatus were not identified to species in the QSCP. (a) QSCP

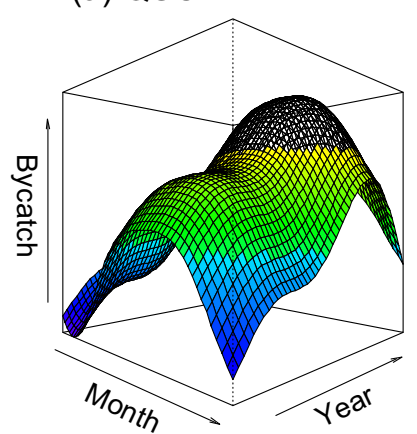

(b) StrandNet

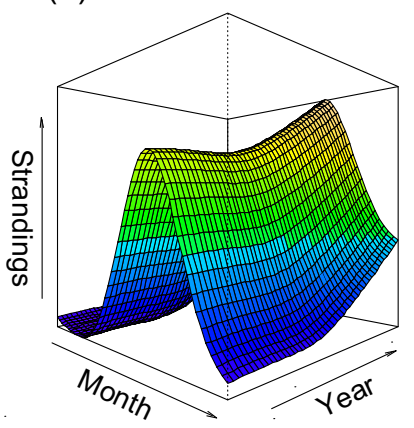

Fig. 5. Seasonality and annual trend in (a) cetacean bycatch in the Queensland Shark Control Program (QSCP) from 1992 to 2012 and (b) strandings in StrandNet from 1996 to 2012. The response surfaces are on the scale of the linear predictor; in figure (a) a negative binomial error was used and in figure (b) data were $\log _{e}(x+1)$ transformed and a Gaussian error distribution was used. In both figures, month was modelled using a cubic spline and is scaled from 1 (January) to 12 (December).

had very little influence on the shape of the fitted model, with a seasonal peak again occurring in August in the reduced model.

\subsection{Size and sex selectivity of QSCP gear}

Bycatch of short-beaked common dolphins was strongly female biased, with close to twice the number of females than males caught, but sex-ratio did not deviate from random for the other five cetacean species tested (Table 1). The sizes (body lengths) of 
Table 1

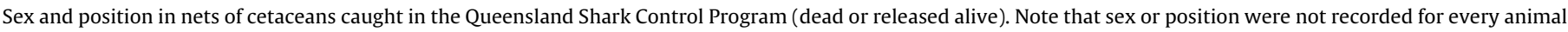
Sex ratios and net positions were compared using binomial tests $\left({ }^{*} p<0.05\right)$

\begin{tabular}{|c|c|c|c|c|c|}
\hline \multirow[t]{2}{*}{ Species } & \multirow[t]{2}{*}{ Common name } & \multicolumn{2}{|l|}{ Sex } & \multicolumn{2}{|l|}{ Position } \\
\hline & & Female & Male & Beach side & Ocean side \\
\hline Tursiops spp. & Bottlenose dolphin & 13 & 10 & 7 & 3 \\
\hline Delphinus delphis & Common dolphin & $66^{*}$ & $34^{*}$ & $22^{*}$ & $42^{*}$ \\
\hline Megaptera novaeangliae & Humpback whale & 4 & 2 & 3 & 3 \\
\hline Sousa sahulensis & Australian humpback dolphin & 7 & 7 & 7 & 5 \\
\hline Orcaella heinsohni & Australian snubfin dolphin & 4 & 2 & 6 & 4 \\
\hline Stenella longirostris & Spinner dolphin & 6 & 7 & 2 & 2 \\
\hline- & Unidentified dolphin & 4 & 9 & 3 & 3 \\
\hline
\end{tabular}

males and females caught in the QSCP did not significantly differ for the 7 taxonomic groups tested ( $t$ tests, $p$ values from 0.15 to 0.99 ).

The length-frequency distributions of short-beaked common dolphins caught in nets or drumlines did not significantly differ $\left(Z=0.9, p=0.37, n_{1}=5, n_{2}=88\right)$. There were not enough data to compare sizes between gear types for the other species. The length-frequency distribution of short-beaked common dolphins, bottlenose dolphins or humpback whales did not significantly differ between the QSCP and strandings datasets (Kruskal-Wallis tests, $p$ values from 0.1 to 0.8 ). However, bycatch of Australian humpback dolphins in the QSCP was skewed towards smaller size classes $(<2 \mathrm{~m})$ compared to the strandings dataset, which was dominated by sizes $>2 \mathrm{~m}$ in body length $\left(Z=11.5, n_{1}=13, n_{2}=70 ; p<0.01\right)$.

Proportionally more short-beaked common dolphins were caught on the ocean side than the beach side of nets, but net side did not deviate from random for the other five other cetacean species tested (Table 1 ).

\subsection{Survival of bycatch in nets and drumlines}

Cetaceans were much more likely to be found alive on drumlines than in nets $(\beta \pm \mathrm{SE}=-3.6 \pm 0.6 ; z=-5.49, p<0.01)$, and this relationship did not significantly differ between regions $(D=14.5, \mathrm{df}=10, p=0.15$ ) or over time (year: $D=1.0, \mathrm{df}=1$, $p=0.32$; years $\times$ region: $D=15.7, \mathrm{df}=11, p=0.15)$. Overall, only $7 \%$ of dolphins $(n=277)$ were released alive from net entanglement, compared to $85 \%$ of dolphins released alive from drumlines $(n=33)$. This trend of low survival in nets and high survival from drumlines was similar for all species of dolphins caught (Table 2). Survival of humpback whales entangled in nets was much greater, with most whales released alive $(91 \%, n=43)$.

\section{Discussion}

Both the strandings and bycatch datasets indicated an increasing trend across the region from 1996 to 2008 . Seasonal patterns were also very similar in both datasets, with peak periods of strandings and bycatch in the coldest months (austral winter to early spring). The strong similarity in temporal patterns between these independent datasets suggests a shared functional explanation. Plausible explanations include (a) increased abundance of cetaceans, (b) increased occupancy of shelf and inshore waters or (c) a common factor increases both vulnerability to incidental capture and stranding. A detailed comparison of the species composition of the strandings and bycatch data provides the first clues towards addressing these explanations.

The increase in QSCP bycatch between 1992 and 2008 was largely attributable to catches of three species: short-beaked common dolphins, bottlenose dolphins and humpback whales; whereas the increase in strandings records was driven largely by inshore dolphin species (Indo-Pacific bottlenose dolphins and Australian humpback dolphins) and humpback whales. Of these species, longterm monitoring data are only available for humpback whales.

Humpback whales interact with QSCP nets during their annual migration between feeding areas in the Antarctic and breeding areas in the Great Barrier Reef region. It was estimated from coastal monitoring of migration from 1987 to 2004 that the eastern Australian (E1) sub-stock is recovering at 10.6 $\pm 0.5 \%$ ( $\pm 95 \%$ confidence intervals, CI) per annum (Paterson et al., 1994; Noad et al., 2011). The most parsimonious explanation for the increase in strandings and entanglement rates of this species is therefore that the number of humpback whales migrating through coastal Queensland waters is increasing.

The numbers of bottlenose dolphins also increased over a similar time period in both datasets, but in this case it is not possible to interpret population trends without identification to species. There has been no reliable long-term monitoring for either the Indo-Pacific (Tursiops aduncus) or common bottlenose (Tursiops truncatus) dolphins in Queensland waters, and comparisons between surveys undertaken in different time periods are confounded by differences in methodology (Ansmann et al., 2013).

Similarly, there has been no long-term monitoring for shortbeaked common dolphin populations in the region, although fine-scale genetic structure has been demonstrated across much of the species' distributional range in Australian waters (Möller et al., 2011; Bilgmann et al., 2014). Even so, the clear trend of increasing bycatch of short-beaked common dolphins across a time period when there was no significant change in strandings in our study does not support the hypothesis that the population was increasing. It is more likely that another factor has increased the rate of

Table 2

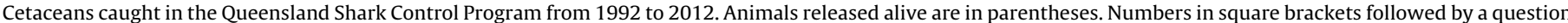
mark: it is uncertain whether the animal was alive or dead.

\begin{tabular}{|c|c|c|c|c|}
\hline Species & Common name & Nets & Drumlines & Gear unknown \\
\hline Tursiops spp. & Bottlenose dolphin & $30(3)$ & $1(12)$ & 1 \\
\hline Delphinus delphis & Common dolphin & $135(7)$ & $1(8)$ & 0 \\
\hline Megaptera novaeangliae & Humpback whale & $4(39)$ & (1) & 0 \\
\hline Sousa sahulensis & Australian humpback dolphin & $24(1)$ & (2) & 3 \\
\hline Orcaella heinsohni & Australian snubfin dolphin & $12(3)$ & 1 & 0 \\
\hline \multirow[t]{2}{*}{ Stenella longirostris } & Spinner dolphin & $15(1)$ & 1 & 0 \\
\hline & Unidentified dolphin & 61(6) [1?] & $1(6)$ & $4[1 ?]$ \\
\hline
\end{tabular}


interactions with QSCP gear, such as greater occupancy of inshore areas. The logical starting point to determine the reasons behind changes in bycatch rates for this species would be the distribution and availability of prey. Short-beaked common dolphins feed mostly on small, shoaling pelagic fish (Meynier et al., 2008; Santos et al., 2013 and references therein) and their distribution is known to be strongly affected by the distribution of prey (Cañadas et al., 2002).

Several observations suggest short-beaked common dolphins interacted with QSCP nets as they approached the shore to feed on pelagic fish. Firstly, they were caught more often on the oceanic side rather than the shore side of the nets. Secondly, they are often observed by QSCP contractors chasing pelagic fish close to nets. Lastly, two post-mortem examinations of short-beaked common dolphins caught in QSCP nets in 2013 indicated that they were feeding on pelagic fish close to the time of death (StrandNet data).

There are no obvious explanations why overall cetacean bycatch in the QSCP declined between 2008 and 2012, while strandings rates continued to increase. The only operational change in the QSCP at the time was the incremental introduction of a new type of $10 \mathrm{kHz}$ dolphin pinger in 2007. However, whether this new pinger reduced rates of bycatch is unknown without a controlled experimental design comparing bycatch in nets with pingers to bycatch in nets without pingers. Further investigation of extrinsic factors influencing bycatch vulnerability in the QSCP is warranted.

\subsection{Seasonality}

Both cetacean bycatch and strandings were under strong seasonal control, with peaks in both datasets in austral winter-early spring. Yet, there were some minor differences in seasonal trends between the datasets on a species-by-species basis. Bycatch of humpback whales occurred mostly during the peak of the southern migration in South-East Queensland (September-October, Brown et al., 1995), when they are considered to be the closest to the shore and most likely to enter coastal embayments such as Hervey Bay and Moreton Bay (Corkeron et al., 1994; Chaloupka et al., 1999; Chilvers et al., 2005). In contrast, strandings rates of humpback whales peaked earlier (August) during the tail end of the northern migration and beginning of the southern migration (Chittleborough, 1965; Paterson et al., 1994), suggesting another explanation. Young calves were proportionally more frequent in the strandings record in August, when 74\% of whales were less $5 \mathrm{~m}$ in length $(n=19)$, compared to $48 \%$ during other months $(n=42)$. Hence, the peak in the strandings rate during August may at least partly be related to seasonal parturition (Chittleborough, 1965) and the general pattern of lower early survival relative to older age classes (Zerbini et al., 2010).

In the case of short-beaked common dolphins, bycatch rates peaked in austral winter, but no seasonality was evident in the strandings record. Our interpretation of this is that they are present in offshore (or neritic) waters year round, but move closer to the shore (where the QSCP gear is deployed) during austral winter. Movements of short-beaked common dolphins between nearshore and offshore waters in other regions are strongly seasonal, and have been attributed to movements of prey or responses to changes in sea-surface temperature (Cockcroft and Peddemors, 1990; Neumann, 2001; Cañadas et al., 2002; Stockin et al., 2008).

\subsection{Selectivity of QSCP gear}

Our comparison between datasets indicated that QSCP gear catches more short-beaked common and spinner dolphins than would be expected based on the strandings data; and the reverse for bottlenose dolphins, humpback whales and species associated with deeper offshore waters (e.g. melon-headed whales).
Understanding why certain species are more prone to interactions with QSCP gear than other species depends on detailed behavioural observations. One suggestion by QSCP contractors is that largely resident bottlenose dolphins have learnt the risks imposed by QSCP nets, while the more wide-ranging pelagic dolphins (spinner and short-beaked common dolphins) are largely naïve to nets that they seldom encounter. Even so, bottlenose dolphins are frequently seen stealing bait from drumlines, and recognisable individuals have been observed to do this repeatedly (Sumpton et al., 2010). This bait stealing behaviour may explain why bottlenose dolphins were caught on drumlines comparatively more often than short-beaked common dolphins (28\% of bottlenose dolphins were caught on drumlines compared to only $6 \%$ of common dolphins).

The fact that fewer humpback whales than expected were caught in the QSCP may reflect size-selectivity well known in the fisheries literature (e.g. Millar and Fryer, 1999). Compared to dolphins, the larger size of humpback whales may make them less likely to become entangled in a net and/or more likely to break away should they become entangled (Cassoff et al., 2011).

The size range of Australian humpback dolphins caught in the QSCP was skewed towards smaller dolphins when compared to the strandings dataset. A similar observation was made for the related species, Sousa plumbea in the shark control program in KwaZuluNatal, South Africa (Atkins et al., 2013), where it was suggested that younger dolphins may have been engaging in more risk-taking behaviour than older individuals.

Most short-beaked common dolphins caught in the QSCP were females. This could suggest sexual segregation with females closer to the shore than males, and/or behaviour differences that make females more vulnerable to entanglement. Sexual segregation in habitat use is widespread amongst cetaceans (Wearmouth and Sims, 2008), and the diet of short-beaked common dolphins differs between sexes in southern Africa (Young and Cockcroft, 1994). Numerous studies have found a sex bias in bycatch in this species in pelagic trawl nets and pelagic gillnets, usually with males being caught more often than females (Fernández-Contreras et al., 2010 and references therein). The nearshore location of QSCP gear may explain the reverse bias observed in the current study. Regardless of the reason for this sex bias, it is relevant for population impact assessments. This is because the loss of a mature female can have a stronger impact than the loss of a mature male (Caswell, 2001), especially if females are pregnant or have a dependent calf (see Wade et al., 2007 for a discussion of cryptic impacts of fisheries bycatch).

Estimates of gear selectivity can be confounded by identification and data-entry errors, even when reports come from trained observers. A comparison of the species composition of bycatch and strandings can help identify anomalies for further investigation, but it is only possible to retrospectively confirm species identify when photos, genetic samples or voucher specimens are available. Distinguishing between common and Indo-Pacific bottlenose dolphins remains a challenge for even experienced observers. It is recommended that training is frequently updated and that genetic samples and photos are taken for species verification whenever possible.

\subsection{Impacts of QSCP on threatened cetacean species}

Three species of cetaceans caught in the QSCP are conservation priorities at state, national and international levels: humpback whales, Australian humpback dolphins and Australian snubfin dolphins (Bannister et al., 1996). The majority of humpback whales that entangle in QSCP gear either escape unaided or are released alive, with an average annual mortality rate of 0.2 whales per year (1992-2012). The population that migrates past the QSCP is considered to be recovering at a rate close to the maximum plausible 
rate of increase (11.8\%, Zerbini et al., 2010). This suggests that the QSCP is unlikely to pose a significant threat to the E1 sub-stock of humpback whales at the present time.

Australian humpback and snubfin dolphins have localised and small sub-population sizes that cannot sustain very high levels of anthropogenic mortality (Parra et al., 2006a, 2006b). Estimates of the population size of discrete populations of humpback dolphins on the Queensland east coast are $\leq 163$ individuals (Corkeron et al., 1997; Parra et al., 2006a; Cagnazzi et al., 2011) and $\leq 105$ individuals for snubfin dolphins (Parra et al., 2006a; Cagnazzi et al., 2013). Low population growth potential (likely to be $\leq 4 \%$ per annum, Reilly and Barlow, 1986; Wade, 1998) and the fact that there are other anthropogenic sources of mortality (e.g. interactions with vessels and fisheries), suggests the need to closely monitor impacts of the QSCP on humpback and snubfin dolphins at a local level.

In the QSCP dataset analysed here (1992-2012), the Cairns nets accounted for most snubfin mortalities (54\% of mortalities), and were replaced with drumlines in 2013. Most mortalities of Australian humpback dolphins were recorded in the nets at Rainbow Beach (44\% of mortalities) and at Cairns (32\% of mortalities). Bycatch of humpback dolphins per unit effort was the highest at Rainbow Beach, from 1998 to 2004, when 11 mortalities were recorded in an area where only three nets were deployed. No catches of humpback dolphins in the area were recorded between 2004 and 2012, and a population assessment conducted from 2004 to 2007 indicated a total population of around 150 individuals in the adjacent Great Sandy Strait (95\% CI from 132 to 165, Cagnazzi et al., 2011).

A range of different strategies have been proposed and implemented regionally to reduce bycatch, including replacing nets with drumlines. However, any steps to reduce bycatch of a given species in the QSCP need to be considered within the context of catches of not only the target shark species, but also other threatened bycatch species including marine turtles, dugongs and elasmobranches (Sumpton et al., 2011). Species differ in vulnerability to particular gear types, and the community of species that interact with QSCP gear varies locally and seasonally. Managing the QSCP is to meet its primary objective of human safety, while also minimising impacts on bycatch species continues to be a significant challenge.

Quantitative assessment of the impacts of the QSCP on cetaceans is also hindered by an absence of data. Little is known of population size or trends of short-beaked common, spinner and common bottlenose dolphins across the region; and key life-history parameters can only be inferred from other stocks or species. Carcasses recovered from bycatch or strandings can yield important information on age and reproductive state, which can supplement mark-recapture surveys or population models (Mannocci et al., 2012).

\section{Conclusions}

A major hurdle in using bycatch per unit effort as an ecological indicator for data-limited cetaceans is that gear selectivity can distort underlying ecological trends. Gear selectivity can also make it difficult to assess the effectiveness of bycatch mitigation. Here we show how a large-scale strandings program can be used to generate indices of species composition and relative abundance in data-limited cetacean communities. This integrated approach draws upon the relative strengths of each approach, i.e. quantitative robustness of standardised bycatch and species composition of the strandings record. In the case of the only species for which simultaneous long-term monitoring was available, humpback whales, all three datasets suggested similar annual trends. However, interpretation is less obvious where trends differ between the strandings and bycatch records, as was the case with short-beaked common dolphins. In this situation, a comparative approach serves to generate testable hypotheses to guide and direct dedicated field surveys. These results highlight the value of accurate and continued recording of bycatch and strandings data, not only to monitor ecological impacts but also to inform science on data-limited species.

\section{Acknowledgements}

The authors would like to thank the Queensland Marine Wildlife Strandings and Mortality network and all contributors to the StrandNet Database. We would also like to thank two anonymous reviewers for helpful comments.

\section{Appendix A. Supplementary data}

Supplementary data associated with this article can be found, in the online version, at http://dx.doi.org/10.1016/j.ecolind.2015. 08.052 .

\section{References}

Anderson, M.J., Gorley, R.N., Clarke, K.R., 2008. PERMANOVA+ for PRIMER: Guide to Software and Statistical Methods. PRIMER-E, Plymouth, UK.

Ansmann, I.C., Lanyon, J.M., Seddon, J.M., Parra, G.J., 2013. Monitoring dolphins in an urban marine system: total and effective population size estimates of IndoPacific bottlenose dolphins in Moreton Bay, Australia. PLoS ONE 8, e65239.

Atkins, S., Cliff, G., Pillay, N., 2013. Humpback dolphin bycatch in the shark nets in KwaZulu-Natal, South Africa. Biol. Conserv. 159, 442-449.

Baker, C.S., Clapham, P.J., 2004. Modelling the past and future of whales and whaling. Trends Ecol. Evol. 19, 365-371.

Bannister, J.L., Kemper, C., Warnecke, R.M., 1996. The Action Plan for Australian Cetaceans. Australian Nature Conservation Agency, Canberra.

Bilgmann, K., Moller, L.M., Harcourt, R.G., Kemper, C.M., Beheregaray, L.B., 2011. The use of carcasses for the analysis of cetacean population genetic structure: a comparative study in two dolphin species. PLoS ONE 6, e20103.

Bilgmann, K., Parra, G.J., Zanardo, N., Beheregaray, L.B., Möller, L.M., 2014. Multiple management units of short-beaked common dolphins subject to fisheries bycatch off southern and southeastern Australia. Mar. Ecol. Prog. Ser. 500, 265-279.

Brown, M.R., Corkeron, P.J., Hale, P.T., Schultz, K.W., Bryden, M., 1995. Evidence for a sex-segregated migration in the humpback whale (Megaptera novaeangliae). Proc. R. Soc. B: Biol. Sci. 259, 229-234.

Cagnazzi, D., Parra, G.J., Westley, S., Harrison, P.L., 2013. At the heart of the industrial boom: Australian snubfin dolphins in the Capricorn Coast, Queensland, need urgent conservation action. PLOS ONE 8, e56729.

Cagnazzi, D.D.B., Harrison, P.L., Ross, G.J.B., Lynch, P., 2011. Abundance and site fidelity of Indo-Pacific humpback dolphins in the Great Sandy Strait, Queensland Australia. Mar. Mamm. Sci. 27, 255-281.

Cañadas, A., Sagarminaga, R., Garcı-Tiscar, S., 2002. Cetacean distribution related with depth and slope in the Mediterranean waters off southern Spain. Deep Sea Res. Part I: Oceanogr. Res. Pap. 49, 2053-2073.

Cassoff, R.M., Moore, K.M., McLellan, W.A., Barco, S.G., Rotsteins, D.S., Moore, M.J. 2011. Lethal entanglement in baleen whales. Dis. Aquat. Organ. 96, 175-185.

Caswell, H., 2001. Matrix Population Models: Construction, Analysis, and Interpretation. Sinauer Associates, Sunderland.

Chaloupka, M., Osmond, M., Kaufman, G., 1999. Estimating seasonal abundance trends and survival probabilities of humpback whales in Hervey Bay (east coast Australia). Mar. Ecol. Prog. Ser. 184, 291-301.

Chilvers, B.L., Lawler, I.R., Macknight, F., Marsh, H., Noad, M., Paterson, R., 2005 Moreton Bay, Queensland, Australia: an example of the co-existence of significant marine mammal populations and large-scale coastal development. Biol Conserv. 122, 559-571.

Chittleborough, R., 1965. Dynamics of two populations of the humpback whale Megaptera novaeangliae (Borowski). Mar. Freshw. Res. 16, 33-128.

Christensen, L.B., 2006. Marine mammal populations: historical abundances at the global scale. Fisheries Centre Research Reports. Fisheries Centre, University of British Columbia, Canada.

Cockcroft, V., Peddemors, V., 1990. Seasonal distribution and density of common dolphins Delphinus delphis off the south-east coast of southern Africa. S. Afr. J. Mar. Sci. 9, 371-377.

Corkeron, P.J., Brown, M., Slade, R.W., Bryden, M.M., 1994. Humpback whales Megaptera novaeangliae (Cetacea, Balaenopteridae), in Hervey Bay, Queensland. Wildl. Res. 21, 293-305.

Corkeron, P.J., Morissette, L., Porter, H., Marsh, H., 1997. Distribution and status of humpback dolphins, Sousa chinesis in Australian waters. Asian Mar. Biol. 14, 49-59. 
Fernández-Contreras, M., Cardona, L., Lockyer, C., Aguilar, A., 2010. Incidental bycatch of short-beaked common dolphins (Delphinus delphis) by pair trawlers off northwestern Spain. ICES J. Mar. Sci. 67, 1732-1738.

Gribble, N.A., McPherson, G., Lane, B., 1998. Effect of the Queensland Shark Control Program on non-target species: whale, dugong, turtle and dolphin: a review. Mar. Freshw. Res. 49, 645-651.

Harley, S.J., Myers, R.A., Dunn, A., 2001. Is catch-per-unit-effort proportional to abundance? Can. J. Fish. Aquat. Sci. 58, 1760-1772.

Kulldorff, M., Heffernan, R., Hartman, J., Assunçao, R., Mostashari, F., 2005. A space-time permutation scan statistic for disease outbreak detection. PLoS Med. 2, e59.

Leeney, R.H., Amies, R., Broderick, A.C., Witt, M.J., Loveridge, J., Doyle, J., Godley, B.J., 2008. Spatio-temporal analysis of cetacean strandings and bycatch in a UK fisheries hotspot. Biodivers. Conserv. 17, 2323-2338.

Lewison, R.L., Crowder, L.B., Read, A.J., Freeman, S.A., 2004. Understanding impacts of fisheries bycatch on marine megafauna. Trends Ecol. Evol. 19, 598-604.

Lien, J., Lane, B., Gribble, N., McPherson, G., 1996. Use of acoustic alarms to reduce humpback whale bycatch in shark control gillnets on Queensland's Gold Coast. In: Gribble, N.G., Lane, B. (Eds.), Second World Fisheries Congress. Department of Primary Industries, Brisbane, Australia, pp. 45-46.

Magera, A.M., Mills Flemming, J.E., Kaschner, K., Christensen, L.B., Lotze, H.K., 2013. Recovery trends in marine mammal populations. PLoS ONE 8, e77908.

Maldini, D., Mazzuca, L., Atkinson, S., 2005. Odontocete stranding patterns in the main Hawaiian islands (1937-2002): how do they compare with live animal surveys? Pac. Sci. 59, 55-67.

Mannocci, L., Dabin, W., Augeraud-Veron, E., Dupuy, J.F., Barbraud, C., Ridoux, V., 2012. Assessing the impact of bycatch on dolphin populations: the case of the common dolphin in the eastern North Atlantic. PLoS ONE 7, e32615.

Marsh, H., De'Ath, G., Gribble, N., Lane, B., 2005. Historical marine population estimates: triggers or targets for conservation? The dugong case study. Ecol. Appl. $15,481-492$.

Maunder, M.N., Punt, A.E., 2004. Standardizing catch and effort data: a review of recent approaches. Fish. Res. (Amst.) 70, 141-159.

Meager, J.J., Limpus, C., 2014. Mortality of inshore marine mammals in eastern Australia is predicted by freshwater discharge and air temperature. PLoS ONE 9, e94849.

Meynier, L., Pusineri, C., Spitz, J., Santos, M.B., Pierce, G.J., Ridoux, V., 2008. Intraspecific dietary variation in the short-beaked common dolphin Delphinus delphis in the Bay of Biscay: importance of fat fish. Mar. Ecol. Prog. Ser. 354, 277-287.

Millar, R.B., Fryer, R.J., 1999. Estimating the size-selection curves of towed gears, traps, nets and hooks. Rev. Fish. Biol. Fish. 9, 89-116.

Möller, L., Valdez, F.P., Allen, S., Bilgmann, K., Corrigan, S., Beheregaray, L.B., 2011. Fine-scale genetic structure in short-beaked common dolphins (Delphinus delphis) along the East Australian Current. Mar. Biol. (Berl.) 158, 113-126.

Neumann, D.R., 2001. Seasonal movements of short-beaked common dolphins (Delphinus delphis) in the north-western Bay of Plenty, New Zealand: influence of sea surface temperature and El Niño/La Niña. N. Z. J. Mar. Freshw. Res. 35, 371-374.

Noad, M.J., Dunlop, R.A., Paton, D., Cato, D.H., 2011. Absolute and relative abundance estimates of Australian east coast humpback whales (Megaptera novaeangliae). J. Cetacean Res. Manag. Spec. Issue 3, 243-252.

Norman, S.A., Huggins, J., Carpenter, T.E., Case, J.T., Lambourn, D.M., Rice, J., Calambokidis, J., Gaydos, J.K., Hanson, M.B., Duffield, D.A., Dubpernell, S., Berta, S. Klope, M., 2012. The application of GIS and spatiotemporal analyses to investigations of unusual marine mammal strandings and mortality events. Mar. Mamm. Sci. 28, 251-266.

Parra, G.J., Corkeron, P.J., Marsh, H., 2006a. Population sizes, site fidelity and residence patterns of Australian snubfin and Indo-Pacific humpback dolphins: implications for conservation. Biol. Conserv. 129, 167-180.

Parra, G.J., Schick, R., Corkeron, P.J., 2006b. Spatial distribution and environmental correlates of Australian snubfin and Indo-Pacific humpback dolphins. Ecography 29, 396-406.
Paterson, R., Paterson, P., Cato, D.H., 1994. The status of humpback whales Megapter novaeangliae in east Australia thirty years after whaling. Biol. Conserv. 70, $135-142$.

Paterson, R.A., 1990. Effects of long-term anti-shark measures on target and nontarget species in Queensland, Australia. Biol. Conserv. 52, 147-159.

Peltier, H., Dabin, W., Daniel, P., Van Canneyt, O., Dorémus, G., Huon, M., Ridoux, V. 2012. The significance of stranding data as indicators of cetacean populations at sea: modelling the drift of cetacean carcasses. Ecol. Indicat. 18, 278-290.

Perrin, W.F., Würsig, B.G., Thewissen, J.G.M., 2002. Encyclopedia of Marine Mammals. Academic Press, San Diego.

Pinheiro, J.C., Bates, D.M., 2000. Mixed-Effects Models in S and S-PLUS. SpringerVerlag New York, Inc, New York, NY.

Pyenson, N.D., 2010. Carcasses on the coastline: measuring the ecological fidelity of the cetacean stranding record in the eastern North Pacific Ocean. Paleobiology $36,453-480$.

Pyenson, N.D., 2011. The high fidelity of the cetacean stranding record: insights into measuring diversity by integrating taphonomy and macroecology. Proc. R. Soc. Lond. B: Biol. Sci. 278, 3608-3616.

R Core Team, 2015. R: A Language and Environment for Statistical Computing. R Foundation for Statistical Computing, Vienna, Austria, https://www.R-project. org/.

Read, A.J., Drinker, P., Northridge, S., 2006. Bycatch of marine mammals in U.S. and global fisheries. Conserv. Biol. 20, 163-169.

Reilly, S.B., Barlow, J., 1986. Rates of increase in dolphin population size. Fish. Bull 84, 527-533.

Santos, M.B., German, I., Correia, D., Read, F.L., Cedeira, J.M., Caldas, M., López, A., Velasco, F., Pierce, G.J., 2013. Long-term variation in common dolphin diet in relation to prey abundance. Mar. Ecol. Prog. Ser. 481, 249-268.

Stockin, K.A., Pierce, G.J., Binedell, V., Wiseman, N., Orams, M.B., 2008. Factors affecting the occurrence and demographics of common dolphins (Delphinus sp.) in the Hauraki Gulf, New Zealand. Aquat. Mamm. 34, 200-211.

Sumpton, W., Lane, B., Ham, A., 2010. Gear modifications and alternative baits that reduce bait scavenging and minimize by-catch on baited drum-lines used in the Queensland shark control program. Proc. R. Soc. Qld. 116, 23-34.

Sumpton, W.D., Taylor, S.M., Gribble, N.A., McPherson, G., Ham, T., 2011. Gear selectivity of large-mesh nets and drumlines used to catch sharks in the Queensland Shark Control Program. Afr. J. Mar. Sci. 33, 37-43

Thompson, K.F., Millar, C.D., Scott Baker, C., Dalebout, M., Steel, D., van Helden, A.L. Constantine, R.,2013. A novel conservation approach provides insights into the management of rare cetaceans. Biol. Conserv. 157, 331-340.

Venables, W.N., Ripley, B.D., 2002. Modern Applied Statistics With S. Springer, New York.

Wade, P.R., 1998. Calculating limits to the allowable human-caused mortality of cetaceans and pinnipeds. Mar. Mamm. Sci. 14, 1-37.

Wade, P.R., Watters, G.M., Gerrodette, T., Reilly, S.B., 2007. Depletion of spotted and spinner dolphins in the eastern tropical Pacific: modeling hypotheses for their lack of recovery. Mar. Ecol. Prog. Ser. 343, 1-14.

Warton, D.I., 2005. Many zeros does not mean zero inflation: comparing the goodness-of-fit of parametric models to multivariate abundance data. Environmetrics 16, 275-289.

Wearmouth, V.J., Sims, D.W., 2008. Sexual segregation in marine fish, reptiles, birds and mammals: behaviour patterns, mechanisms and conservation implications. Adv. Mar. Biol. 54, 107-170.

Wood, S.N., 2006. Generalized Additive Models: An Introduction With R. Chapman \& Hall/CRC, Boca Raton.

Young, D.D., Cockcroft, V.G., 1994. Diet of common dolphins (Delphinus delphis) of the south-east coast of Southern Africa: opportunism or specialization? J. Zool. $234,41-53$

Zerbini, A.N., Clapham, P.J., Wade, P.R., 2010. Assessing plausible rates of population growth in humpback whales from life-history data. Mar. Biol. (Berl.) 157, 1225-1236. 